\title{
A EDUCAÇÃO (EM TEMPO) INTEGRAL NO BRASIL: UM OLHAR SOBRE DIFERENTES EXPERIÊNCIAS ${ }^{l}$
}

\author{
EDUCACIÓN (DE TIEMPO) COMPLETO EN BRASIL: UN ENFOQUE SOBRE \\ EXPERIENCIAS DISTINTAS
}

(FULL-TIME) EDUCATION IN BRAZIL: A VIEW OF DIFFERENT EXPERIENCES

\author{
Mariana Lubarino VILAS BOAS ${ }^{2}$ \\ Andréia Silva ABBIATI ${ }^{3}$
}

RESUMO: Os projetos de educação em tempo integral desenvolvidos por Anísio Teixeira (1950) e Darcy Ribeiro (1980) impulsionaram diferentes experiências educacionais no Brasil. Em vista disto, apresenta-se como objetivo deste artigo analisar algumas dessas experiências à luz de artigos científicos disponibilizados na plataforma da biblioteca online SciELO, no período de 2002 a 2019. A análise revelou que as concepções de educação integral e de educação em tempo integral permeiam as discussões e provocam dúvidas quanto à função social da educação em tempo integral. Além disso, a falta de infraestrutura das escolas de tempo integral é frequentemente apontada como fator impeditivo à realização de atividades primordiais desta forma de organização do ensino. Considera-se que são necessários maiores aportes de investimentos para que a jornada escolar ampliada cumpra seu papel transformador na educação brasileira, ou seja, a formação integral do estudante.

PALAVRAS-CHAVE: Educação em tempo integral. Educação integral. Experiências de educação em tempo integral.

RESUMEN: Los proyectos de educación de tiempo completo desarrollados por Anísio Teixeira (1950) y Darcy Ribeiro (1980) impulsaron experiencias educacionales distintas en Brasil. Teniendo eso en cuenta, se presenta como objetivo de este artículo, analizar algunas de esas experiencias a la luz de artículos científicos disponibles en la plataforma de la biblioteca en línea SciELO, en el periodo de 2002 a 2019. El análisis enseñó que las concepciones de educación integral y educación de tiempo completo permean las discusiones y provocan en lo que respecta a función social de la educación en tiempo completo. Además, la falta de infraestructura de las escuelas de tiempo completo es frecuentemente apuntada como factor que impide la realización de las actividades primordiales en esta forma de organización de enseñanza. Se consideran necesarios aportes más altos de inversiones para que la jornada escolar ampliada cumpla su papel transformador en la educación brasileña, es decir, la formación integral del estudiante.

\footnotetext{
${ }^{1}$ Pesquisa financiada pelo IFSP.

${ }^{2}$ Instituto Federal de Educação Ciência e Tecnologia de São Paulo (IFSP), São João da Boa Vista - SP - Brasil. Graduanda em Ciências Naturais. ORCID: https://orcid.org/0000-0002-6734-0988. E-mail: mariana.1@aluno.ifsp.edu.br

${ }^{3}$ Instituto Federal de Educação Ciência e Tecnologia de São Paulo (IFSP), São João da Boa Vista - SP - Brasil. Professora Adjunta do IFSP. Doutorado em Educação (UNICAMP). ORCID: https://orcid.org/0000-0003-35571279. E-mail: andreia.abbiati@ifsp.edu.br
} 
PALABRAS CLAVE: Educación de tiempo completo. Educación integral. Experiencias de educación de tiempo completo.

ABSTRACT: Full-time education projects that were developed by Anisio Teixeira (1950) and Darcy Ribeiro (1980) promoted different educational experiences in Brazil. Taking this into account, this paper aims to analyze some of these experiences by the light of scientific articles that are available on the SciELO online library platform from 2002 to 2019. The analysis revealed that the conceptions of full education and full-time education permeate discussions and stimulate doubts regarding the social purpose of full-time education. Besides that, the lack of infrastructure for full-time education at schools is frequently pointed out as an obstacle to performing some key activities of this type of teaching organization. Higher investments are taken as necessary so that the longer school days meet the role inside the Brazilian education system, it means, the complete development of their students.

KEYWORDS: Full-time education. Full education. Full-time education experiences.

\section{Introdução}

Desde a aprovação da Lei de Diretrizes e Bases da Educação Nacional (LDBEN), Lei n. 9.394/1996, o planejamento de políticas públicas de educação em tempo integral vem sendo estimulado em nosso país. Recentemente, o Plano Nacional de Educação (PNE), aprovado para o decênio 2014-2024, previu, em sua meta 6, “oferecer educação em tempo integral em, no mínimo, 50\% (cinquenta por cento) das escolas públicas, de forma a atender, pelo menos, $25 \%$ (vinte e cinco por cento) dos(as) alunos(as) da educação básica" (BRASIL, 2014), ampliando, ainda mais, o compromisso dos entes federados com a extensão da jornada escolar de crianças e adolescentes do nosso país.

No Brasil, as primeiras experiências de ampliação da jornada escolar datam dos anos de 1950, quando Anísio Teixeira, um dos impulsionadores do Movimento da Escola Nova ${ }^{4}$, inaugurou o Centro Educacional Carneiro Ribeiro, também conhecido como Escola Parque, em Salvador, na Bahia.

O crescimento da indústria e da vida urbana contribuíram para o modelo educacional proposto por Anísio Teixeira, pois a educação não poderia ser especializada tão somente no preparo de intelectuais, devendo também formar trabalhadores (TEIXEIRA, 1994). O

${ }^{4}$ O Movimento da Escola Nova ocorreu no Brasil na década de 1930. Este criticava o modelo tradicional de ensino e colocava o aluno como centro do processo de ensino-aprendizagem. O movimento ganhou força a partir da publicação do Manifesto dos Pioneiros da Escola Nova em 1932 - documento que definia diretrizes para a política de educação. Anísio Teixeira estava entre os 26 escritores deste documento, sendo um dos principais pioneiros da Escola Nova (CURY; CUNHA, 2015). 
conhecimento profissional tornou-se uma necessidade e a ampliação da jornada escolar poderia atendê-lo, oferecendo às crianças e jovens das camadas populares atividades voltadas para o mundo do trabalho.

De acordo com a concepção de Anísio Teixeira, a extensão da jornada escolar traria novas oportunidades para a educação pública brasileira, minimizando a evasão escolar e o fracasso da escola pública, conforme registros de Cavaliere (2010). Assim, a experiência desenvolvida em Salvador poderia contribuir para solucionar o problema da educação no Brasil, pois através do período integral poder-se-ia atender aos objetivos da nova sociedade, movida por interesses econômicos (TEIXEIRA, 1994).

A Escola Parque oferecia cursos profissionalizantes de desenho, modelagem em cerâmica, corte e costura, marcenaria, trabalho sobre couro, tapeçaria e tecelagem. Os alunos formados em cursos profissionalizantes atuariam no mercado de trabalho, contribuindo, assim, com as necessidades da sociedade contemporânea (SANTOS, 2009).

Inspirado em Anísio Teixeira, Darcy Ribeiro, durante os anos de 1980, no Rio de Janeiro (RJ), inaugurou os Centros Integrados de Escola Pública - CIEPs. Uma das diferenças entre os CIEPs e o Centro Educacional Carneiro Ribeiro, era que as atividades dos CIEPS ocorriam no mesmo espaço, isto é, no mesmo prédio. Já o Centro Educacional Carneiro Ribeiro era dividido em Escolas-Classe e Escola Parque.

O modelo educacional de Anísio Teixeira era composto por quatro EscolasClasse, onde cerca de 500 alunos em cada uma delas recebiam em um turno o ensino dos conteúdos tradicionais e, no contraturno, almoçavam na Escola Parque e participavam de atividades culturais, esportivas, artísticas, sociais e de iniciação ao trabalho. Além das atividades escolares os alunos recebiam atendimento médico e odontológico. O complexo da Escola Parque atendia mil alunos por turno (BRANCO, 2012, p. 113-114).

Além dos conteúdos tradicionais (disciplinas científicas, acadêmicas), tanto a Escola Parque como os CIEPs, ofereciam também diversos tipos de atividades, alimentação e atendimento médico e odontológico. Ao sujeito eram satisfeitas as necessidades intelectuais, físicas, culturais e morais, ou seja, uma formação integral do educando.

Abordar a questão da educação em tempo integral (ETI) envolve entender que esta é diferente da educação integral. Ambos os termos, apesar de parecidos, remetem a significados distintos. A ampliação da jornada escolar não pode ser entendida como a formação integral do sujeito, mesmo sendo importante neste processo.

A educação integral trabalha a multidimensionalidade do sujeito, compreendendo o seu aspecto intelectual, físico e emocional. Entende o indivíduo de forma integral e busca 
desenvolver atividades que abordem a multidimensionalidade que lhe pertence (GONÇALVES, 2006).

[...] o sujeito multidimensional é um sujeito desejante, o que significa considerar que, além da satisfação de suas necessidades básicas, ele tem demandas simbólicas, busca satisfação nas suas diversas formulações de realização, tanto nas atividades de criação quanto na obtenção de prazer nas mais variadas formas (GONÇALVES, 2006, p. 130).

De acordo com Gonçalves (2006, p. 131), “[...] aquilo que é proposto como conteúdo escolar, curricular, só poderá ser significativo se dialogar com os interesses do grupo, seus conhecimentos prévios, seus valores e seu cotidiano". O ensino é mais eficaz quando se trabalha os interesses dos alunos e para isso é necessário compreender o sujeito multidimensional e levar em conta todas as suas vivências e experiências ao longo do tempo (GONÇALVES, 2006).

Independente da integralidade da formação, a duração do turno escolar, traduzido em tempo que o aluno passa na escola, também é objeto de discussão. A educação em tempo integral pode significar meramente uma forma de organização escolar em jornada ampliada, oferecendo diferentes atividades em seu contraturno escolar, mas sem o sentido da formação integral do sujeito. Anísio Teixeira defende a ampliação da jornada escolar especialmente para a escola primária ${ }^{5}$ :

A educação comum, para todos, já não pode ficar circunscrita à alfabetização ou à transmissão mecânica das três técnicas básicas da vida civilizada - ler, escrever e contar. Já precisa formar, tão solidamente quanto possível, embora em nível elementar, nos seus alunos, hábitos de competência executiva, ou seja, eficiência de ação; hábitos de sociabilidade, ou seja, interesse na companhia de outros, para o trabalho ou o recreio; hábitos de gosto, ou seja, de apreciação da excelência de certas realizações humanas (arte); hábitos de pensamento e reflexão (método intelectual) e sensibilidade de consciência para os direitos e reclamos seus e de outrem [...]. Somente escolas destinadas a fornecer informações ou certos limitados treinamentos mecânicos podem ainda admitir o serem de tempo parcial.

A escola primária, visando, acima de tudo, a formação de hábitos de trabalho, de convivência social, de reflexão intelectual, de gosto e de consciência não pode limitar as suas atividades a menos que o dia completo. Devem e precisam ser de tempo integral para os alunos e servidas por professores de tempo integral (TEIXEIRA, 1994, p. 105).

No excerto acima, observa-se que Anísio compreende a educação em tempo integral como uma importante ferramenta para se desenvolver no educando a formação de hábitos de trabalho, convivência social, gosto e consciência, não sendo somente dedicada ao ensino

${ }^{5}$ Refere-se ao primeiro estágio de ensino das crianças na escola, geralmente iniciado a partir dos 6 anos. Com a aprovação da LDBEN de 1996, esta etapa refere-se aos anos iniciais do ensino fundamental. 
objetivo das disciplinas escolares. Portanto, tem-se a educação integral de tempo integral, onde a multidimensionalidade do sujeito é compreendida e trabalhada em jornada estendida.

Diante do exposto, o presente trabalho, resultado de uma pesquisa de Iniciação Científica fomentada pelo Instituto Federal de Educação, Ciência e Tecnologia de São Paulo (IFSP), objetiva analisar algumas das experiências de educação (em tempo) ${ }^{6}$ integral no Brasil, por meio da revisão bibliográfica de artigos científicos publicados no período de 2002 a 2019. Para tanto, definiu-se a SciELO$^{7}$ (Scientific Electronic Library Online, traduzido para o português - Biblioteca Eletrônica Científica Online) como a fonte de dados a ser utilizada na pesquisa.

Neste cenário de debates entre diferentes concepções sobre a educação (em tempo) integral, apresentam-se neste trabalho as etapas de levantamento e seleção dos artigos analisados sobre a educação (em tempo) integral. Os artigos foram separados em unidades temáticas e relacionados entre si a fim de se obter uma comparação concisa entre as ideias apresentadas pelos diferentes autores. São também apresentadas as unidades temáticas, assim como a conclusão final sobre a bibliografia estudada.

\section{Metodologia de pesquisa: levantamento de artigos científicos}

O levantamento de artigos científicos ocorreu durante o mês de setembro de 2019 na plataforma da SciELO. Escolheu-se a SciELO por possuir um amplo diretório de artigos relacionados à educação e filtros de pesquisa que ajudam a selecionar apenas os artigos que retratam o tema estudado, facilitando assim a busca dos artigos científicos.

Para a busca de artigos relacionados à temática educação (em tempo) integral, selecionou-se algumas palavras-chaves, sendo: educação integral, educação de tempo integral, educação em tempo integral, escola integral, escola de tempo integral e escola em tempo integral.

As palavras-chave foram inseridas na plataforma redigidas entre aspas (“"), pois estas funcionam como uma importante ferramenta de pesquisa, auxiliando na busca efetiva do termo. A utilização de aspas permite que a palavra-chave seja procurada da mesma forma que foi inserida na base de dados ${ }^{8}$. Por exemplo, ao se pesquisar "educação em tempo integral" entre

${ }^{6}$ Utilizou-se o termo (em tempo) entre parênteses de forma a estudar tanto as experiências de educação integral em tempo integral como somente as de educação em tempo integral.

${ }^{7}$ Veja mais sobre a SciELO em: http://www.scielo.br/?lng=pt.

${ }^{8}$ Uma base de dados se refere a uma fonte de informação computadorizada que contém um amplo diretório de artigos, textos e publicações sobre os mais variados temas. Ao se inserir um termo numa base como a da SciELO, ela percorre todo o seu sistema e retorna os artigos relacionados ao termo utilizado na busca (GOOGLE). 
aspas, o termo resultará em artigos que o contenham exatamente dessa forma. Sem o uso dessa ferramenta, surgem resultados relacionados aos termos "integral", "educação", "tempo", sem, necessariamente, relacionarem-se.

Além das palavras-chave inseridas entre aspas na plataforma, utilizou-se outros filtros de busca como forma de delimitar os resultados. A plataforma da SciELO implementa diferentes filtros que possuem como função auxiliar o(a) pesquisador(a) durante a busca, a fim de restringir o número de publicações retornadas na pesquisa. Alguns tipos de filtros são: idiomas, ano de publicação, coleções, áreas temáticas, tipo de literatura, entre outros.

Escolheu-se o filtro de idioma, selecionando-se o português; como área temática optouse por "ciências humanas" e como categorias temáticas "educação e pesquisa educacional" e “educação e disciplinas científicas". Esse filtro possibilitou um retorno de artigos voltados para a área da pesquisa, no caso, educação. Além destes, utilizou-se o filtro tipo de literatura, definido como "artigo". Os filtros foram selecionados de forma a serem retornados artigos relacionados à educação (em tempo) integral no Brasil.

Cada palavra-chave pesquisada gerou um determinado número de artigos. A partir da análise dos títulos, identificou-se alguns artigos repetidos, os quais foram excluídos do levantamento manualmente, obtendo-se, assim, um retorno de 58 (cinquenta e oito) artigos únicos. Esses 58 (cinquenta e oito) foram submetidos à análise criteriosa, sendo realizada a leitura dos seus resumos, assim como a dos textos na íntegra.

\section{Seleção dos artigos científicos: leitura, fichamentos e unidades temáticas}

A partir da análise dos 58 (cinquenta e oito) artigos obtidos na biblioteca da SciELO, foram selecionados o total de 22 (vinte e dois) artigos. O restante, 36 (trinta e seis) artigos, foram excluídos. O critério estabelecido para a seleção dos artigos foi a ocorrência direta no texto de relatos de experiências de educação (em tempo) integral desenvolvidas no Brasil. Todos os artigos que continham estes relatos foram mantidos, sendo eliminados os que não atendiam diretamente a este critério.

Conforme descrito por Marconi e Lakatos (2010), foi realizada a compilação dos artigos selecionados, ou seja, a reunião sistemática do material. A compilação pode ser realizada por meio de fotocópias, microfilmes, entre outros (MARCONI; LAKATOS, 2010). Escolheu-se fazer o download e imprimir o material para o andamento das etapas posteriores.

Seguindo a metodologia proposta por Marconi e Lakatos (2010), fez-se o fichamento das obras selecionadas. O fichamento é importante para que haja organização das informações 
essenciais ao trabalho. Optou-se por realizar o fichamento de resumo ou de conteúdo, que apresenta de forma clara e resumida as principais ideias do autor e os aspectos importantes da obra. Nas fichas de resumo encontram-se todas as informações importantes dos artigos, facilitando na hora da escolha de uma obra como referência (MARCONI; LAKATOS, 2010).

Sobre este tipo de fichamento, de acordo com Medeiros (2006, p. 121), “o resumo é uma paráfrase e pode-se dizer que dele não devem fazer parte comentários e que engloba duas fases: a compreensão do texto e a elaboração de um novo". Portanto, a ficha de resumo apresenta uma síntese das ideias do autor a partir da compreensão do texto lido.

Para a elaboração dos fichamentos foi realizada, novamente, a leitura completa dos textos e anotações dos aspectos importantes observados durante a mesma. Após, transcreveuse nas fichas um resumo sobre o artigo, contendo o objetivo do mesmo e as suas principais informações, como a metodologia adotada, dados apresentados e relatos de entrevistas.

Os artigos selecionados foram agrupados em cinco unidades temáticas, sendo: (1) A organização dos espaços e tempos da ETI, contendo dois artigos; (2) A ETI e a construção de territórios educativos, com 2 artigos; (3) A gestão escolar e a ETI, também com 2 artigos; (4) Investigações e resultados sobre diferentes experiências da ETI, contendo 12 artigos e (5) Organização dos conhecimentos e saberes na ETI, com 4 artigos, temáticas estas que passamos a analisar na próxima seção deste trabalho

\section{A organização dos espaços e tempos da ETI}

A meta 6 do PNE apresenta dois objetivos 9: “oferecer em, no mínimo, 50\% das escolas públicas jornadas diárias de sete horas ou mais até 2024" e "garantir que, no mínimo, 25\% dos alunos da Educação Básica sejam atendidos em jornadas diárias de sete horas ou mais até 2024" (BRASIL, 2018). A Lei no . 12.796, de 4 de abril de 2013 altera a LDBEN, incluindo em relação a educação infantil, no seu Artigo 31, inciso III: “atendimento à criança de, no mínimo, 4 (quatro) horas diárias para o turno parcial e de 7 (sete) horas para a jornada integral”. Portanto, a educação (em tempo) integral possui uma carga horária de pelo menos 7 (sete) horas diárias de atividades. Os artigos desta unidade abordam a opinião dos alunos sobre a organização do espaço e do tempo na escola de tempo integral.

9 Os objetivos da meta 6 constam no Observatório do PNE. Disponível em: https://www.observatoriodopne.org.br/indicadores/metas/6-educacao-integral/indicadores. Acesso em: 2 abr. 2020. 
No artigo de Souza (2018) utiliza-se como metodologia a adaptação de balanços de saber $^{10}$ e entrevistas com os alunos. Este balanço de saber questionava o aluno sobre as aprendizagens na ETI, o que ainda desejava aprender na escola e o que poderia aprender em outros lugares, se permanecesse menos tempo na escola. A partir da análise de 186 balanços de saber respondidos pelos alunos, destacam-se tensões entre os tempos da escola e os tempos do corpo, a distribuição das atividades ao longo do dia (manhã e tarde) e o excesso de atividades que priorizam a mente (SOUZA, 2018).

Souza (2018) debate sobre a questão da disposição dos alunos para atividades intelectuais e corporais em determinado horário. Geralmente, as disciplinas escolares são realizadas no período da manhã, depois há um horário reservado para o almoço e no período da tarde são realizadas oficinas e práticas esportivas.

No período vespertino, os alunos enfatizam o cansaço em participar das atividades, o sono que sentem e a falta de vontade de praticar algum esporte. Alguns dos balanços de saber trazem a questão da inversão dos horários, podendo ser desenvolvidas as práticas esportivas no período matutino e as disciplinas escolares no período vespertino. Além disso, o estudo apresentou o excesso de disciplinas escolares e a diminuição de atividades voltadas para o corpo (SOUZA, 2018).

Observa-se então que a organização dos espaços e tempos da educação integral nem sempre beneficiam os alunos. A ampliação da jornada escolar nem sempre leva em conta a multidimensionalidade do sujeito, os fatores biológicos que também lhe fazem parte (SOUZA, 2018).

O artigo de Torales (2012) discute a questão de "horas concretas", ou seja, o período de permanência dos estudantes e o sentido atribuído por eles em relação ao horário. Esta presencialidade, ou seja, o longo período de permanência no espaço escolar envolve implicações, pois não se pode pensar apenas no tempo de permanência dos alunos na escola e sim nas atividades a serem desenvolvidas neste período.

Torales (2012) menciona a necessidade de melhorias físicas e materiais no espaço escolar de acordo com a realidade da escola. Nesse sentido, se uma escola possui um espaço pequeno e não oferece nenhuma estrutura acústica, não seria lógico adquirir instrumentos musicais caríssimos, mas a unidade escolar pode procurar se adaptar para a realização das atividades (TORALES, 2012).

${ }^{10}$ Os balanços de saber foram desenvolvidos por Bernard Charlot. São obtidos através de questões norteadoras disponibilizadas para os alunos. Eles recebem essas questões e as respondem produzindo um texto, a partir deste analisa-se a opinião dos alunos sobre determinado assunto (CHARLOT, 2009). 
Os artigos desta unidade apresentam reflexões relacionadas à organização dos horários, que podem ser programados de forma a serem melhor aproveitados pelos alunos. Torna-se necessário pensar no cansaço e na disposição dos sujeitos para realizarem determinadas atividades em um horário específico. A organização do espaço envolve basicamente melhorias na infraestrutura e na aquisição de materiais.

Um questionamento válido é se as escolas oferecem uma infraestrutura adequada para a permanência de alunos por um período de 7 (sete) horas ou mais naquele espaço, pois é necessário que o espaço físico e os materiais sejam adequados para a realização das atividades programadas.

\section{A ETI e a construção de territórios educativos}

Esta unidade retrata a importância de se potencializar os vínculos de pertencimento dos alunos ao espaço do bairro e da comunidade ao redor da escola. As experiências relatadas apontam parcerias que podem ser adotadas pelas escolas com a finalidade de promover o acesso do aluno aos espaços culturais e de interação social da região em que vivem.

Leite e Carvalho (2016) apresentam a experiência de educação integral desenvolvida em Belo Horizonte (MG) pelo Programa Escola Integrada (PEI), no bairro do Alto Vera Cruz. Esta experiência demonstra como a aproximação da comunidade do bairro com a escola contribui para a educação integral, pois valoriza-se a identidade territorial e a cultura local.

Belo Horizonte faz parte do movimento "Cidades Educadoras"11, o qual propõe que as cidades aproveitem todos os seus espaços como centros educativos. A comunidade local, instituições e organizações da sociedade civil e as Organizações Não Governamentais (ONGs) podem apoiar o movimento e contribuir para a construção de um território educativo. Experiências como essa mostram que a escola pode contar com a contribuição de outras instituições e da comunidade a fim de favorecer a formação integral dos alunos.

Leite (2012) relata as experiências de Belo Horizonte (MG) e Santarém (PA), nas quais busca-se a constituição de territórios educativos na perspectiva da educação integral e da cidadania. A experiência desenvolvida em Santarém desenvolve projetos fora do espaço

11 “[...] movimento que teve início em 1990 na cidade de Barcelona e hoje é realidade em várias cidades do mundo. Este movimento se iniciou no I Congresso Internacional de Cidades Educadoras, espaço no qual um grupo de cidades, inclusive Belo Horizonte, representadas por seus governos locais, se reuniram e estabeleceram um pacto com o objetivo de trabalhar em conjunto, desenvolvendo projetos e atividades que buscassem a melhoria da qualidade de vida dos habitantes. Assim, a intenção era a participação ativa dos cidadãos no desenvolvimento da própria cidade, de acordo com a carta das Cidades Educadoras redigida na ocasião" (LEITE; CARVALHO, 2016, p. 1207). 
escolar, como o projeto Arte na Escola da Gente, que é levado por meio de caravanas até as comunidades ribeirinhas, situadas em rios e planaltos. Este projeto desenvolve atividades em toda cidade, como Mostras Culturais, Festival de Interpretação Musical, entre outros, mostrando a preocupação em levar arte e cultura para todas as comunidades.

Em Belo Horizonte, como citado anteriormente, é desenvolvido o PEI, que oferece 9 horas diárias de atendimento às crianças e jovens. Este programa, conta com o apoio de diversos parceiros externos à escola, instituições e organizações da sociedade civil, há também uma parceria com o museu a céu aberto Inhotim, localizado em Brumadinho (MG) (LEITE, 2012). Os municípios de Belo Horizonte e Santarém, apesar de situados em regiões muito diferentes, conseguem desenvolver projetos que dialogam com as comunidades e com o território fora do espaço escolar.

Estas experiências relatadas por Leite e Carvalho (2016) e Leite (2012) apontam para a conexão entre a escola e a vida, pois a aprendizagem social obtida por meio do convívio com a comunidade e com a cidade, assim como a aprendizagem escolar estão conectadas, estabelecendo, assim, um território educativo. Este promove os direitos dos sujeitos em usufruir de todo o espaço territorial em que vivem, representando uma educação que ultrapassa os muros da escola.

\section{A gestão escolar e a ETI}

A gestão escolar coordena a administração, o desenvolvimento dos objetivos e a melhoria na qualidade do ensino da escola. A preocupação com a qualidade do ensino deve levar em conta a estrutura administrativa em conjunto com a estrutura didática, o que demanda uma gestão democrática (PARO, 2009).

Bernardo e Christovão (2016) analisam o desenvolvimento do Programa Mais Educação $(\mathrm{PME})^{12}$ e o Índice de Desenvolvimento da Educação Básica (IDEB) ${ }^{13}$ em busca da qualidade

12 “O Programa Mais Educação, criado pela Portaria Interministerial n’ 17/2007 e regulamentado pelo Decreto 7.083/10, constitui-se como estratégia do Ministério da Educação para indução da construção da agenda de educação integral nas redes estaduais e municipais de ensino que amplia a jornada escolar nas escolas públicas, para no mínimo 7 horas diárias, por meio de atividades optativas nos macrocampos: acompanhamento pedagógico; educação ambiental; esporte e lazer; direitos humanos em educação; cultura e artes; cultura digital; promoção da saúde; comunicação e uso de mídias; investigação no campo das ciências da natureza e educação econômica" (BRASIL, 2018).

13 “O Índice de Desenvolvimento da Educação Básica (IDEB) foi criado em 2007 e reúne, em um só indicador, os resultados de dois conceitos igualmente importantes para a qualidade da educação: o fluxo escolar e as médias de desempenho nas avaliações. Ele é calculado a partir dos dados sobre aprovação escolar, obtidos no Censo Escolar, e das médias de desempenho nas avaliações do Inep, o Sistema de Avaliação da Educação Básica (Saeb) - para as unidades da federação e para o país, e a Prova Brasil - para os municípios” (BRASIL, 2019). 
da educação, no município do Rio de Janeiro $(\mathrm{RJ})$ em relação à gestão democrática e à educação (em tempo) integral. Segundo os autores, a gestão democrática é voltada para a participação de toda a comunidade escolar, no processo de tomada de decisões, reflexões e mudanças.

Hoje, no Brasil, muito se fala em gestão democrática, mas a democracia não se constrói apenas com discurso, necessita de ações e de práticas que possam fortificá-la. E isso costuma levar tempo. Para se exercitar a democracia, é preciso criar espaços para a participação de todos na escola. Porém, não vale estar apenas presente fisicamente, é preciso aprender a questionar e a interferir. Gestores, pais, alunos, professores, enfim, toda a comunidade escolar, deve ser capaz de reivindicar, planejar, decidir, cobrar e acompanhar ações concretas em benefício de todos, exercendo verdadeiramente a cidadania (BERNARDO; CHRISTOVÃO, 2016, p. 1134).

De acordo com Bernardo e Christovão (2016), a gestão democrática passa a ser vista como ferramenta de descentralização das responsabilidades administrativas, com o Estado ainda mantendo um controle dos resultados por meio da centralização da avaliação e das metas:

[...] o Mais Educação agrega à antiga noção de gestão democrática, a perspectiva de que os territórios que conformam as cidades podem e devem constituir-se em espaços educativos, ampliando consequentemente, o tempo de escolarização dos alunos (BERNARDO; CHRISTOVÃO, 2016, p. 1135).

“As redes de Educação Integral no Distrito Federal sob o prisma da Gestão Escolar" elaborado por Souza, Guimarães e Zardo (2018) aborda o Projeto de Educação Integral em Tempo Integral (PROETI) e o modelo de gestão escolar das redes analisadas. Os autores consideram que o modelo de educação integral ideal é aquele que trabalha com um modelo de gestão integral, ou seja, que considere a interação entre todos os atores e a educação integral.

Comparando os dois artigos desta unidade, observa-se que ambos abordam a questão da gestão democrática para o bom funcionamento da educação (em tempo) integral. Para Souza, Guimarães e Zardo (2018) a gestão local deve se comunicar com a comunidade e assim estabelecer vínculos para a participação de todos no planejamento escolar.

Considera-se que a educação integral só se faz com a participação integral da escola com a comunidade e que a gestão democrática pode contribuir para o aumento das metas do IDEB e da qualidade do ensino de uma determinada unidade escolar (BERNARDO; CHRISTOVÃO, 2016). 


\section{Investigações e resultados sobre diferentes experiências da ETI}

Esta unidade abrange, de forma geral, experiências de educação (em tempo) integral. Os artigos são investigações que apresentam diferentes temas, tais como ludicidade, opinião dos alunos sobre a educação (em tempo) integral, os desafios desta concepção de ensino e os resultados alcançados em diferentes experiências de educação (em tempo) integral desenvolvidas no Brasil.

Azevedo e Betti (2014) estudam o Programa de Educação Integrada Cidadescola desenvolvido no município de Presidente Prudente (SP). Os autores investigam os pontos de vista das crianças sobre a educação (em tempo) integral, principalmente sobre a ludicidade (jogos e brincadeiras) presente nesta forma de organização do ensino.

O Programa de Presidente Prudente insere a ludicidade no contraturno escolar, sem estabelecer conexão entre a educação de tempo integral com a educação integral - as atividades permanecem separadas e não integradas. De acordo com Azevedo e Betti (2014) a escola ainda não reconhece a importância das atividades lúdicas para a aprendizagem das crianças, apontando que apenas ampliar a jornada escolar sem promover conexões entre as atividades não contribui para o ensino-aprendizagem.

São analisadas por Coelho, Marques e Branco (2014) duas experiências de educação integral implantadas, entre os anos de 2005-2008, anteriores ao Programa Mais Educação, pelos municípios de Juiz de Fora, no Estado de Minas Gerais (MG), e de Porecatu, no Estado do Paraná (PR).

Para as autoras "cabe à escola, por meio de seu projeto pedagógico, optar pela ampliação da jornada escolar, constituindo uma formação, o mais completa possível, para o aluno que ali se encontra" (COELHO; MARQUES; BRANCO, 2014, p. 373). Estas experiências consideraram a escola como locus central de uma formação mais completa em tempo ampliado. Observa-se, então, a importância da escola na formação integral dos indivíduos.

Coelho (2012) discute concepções de educação integral a partir da visão de alunos do ensino fundamental. A autora realiza entrevistas com alunos de três municípios distintos, sendo estes da região nordeste e sudeste do Brasil. Os nomes dos municípios não são divulgados, apenas algumas informações sobre o espaço geográfico e o sistema educativo das cidades.

$\mathrm{Na}$ análise das entrevistas, Coelho (2012) organiza as opiniões dos alunos sobre a ampliação da jornada escolar em três justificativas: “(1) fatores intrínsecos à natureza da escola; (2) fatores correlatos ao papel da escola contemporânea e (3) fatores essenciais ao entendimento da natureza da Educação Integral" (COELHO, 2012, p. 79). 
As respostas presentes na primeira justificativa correlacionam a ampliação da jornada escolar diretamente à aprendizagem, ao fato de aprenderem muitas coisas, atividades como informática, pintura e música. Na segunda justificativa, os alunos dão respostas relacionadas aos fatores de risco social. Nessa visão, a escola (em tempo) integral tem como papel tirar as crianças da rua, para que elas possam ficar em um espaço seguro. Por meio da segunda justificativa, pode-se observar que a sociedade contemporânea ampliou as funções sociais da escola. Na terceira justificativa, os alunos evidenciam que não possuem as coisas oferecidas na escola (em tempo) integral em casa, como um computador, podendo usufruir deste material durante as aulas (COELHO, 2012).

A autora conclui por meio da análise das respostas dos alunos, que eles conseguem perceber as atividades desenvolvidas como constitutivas de sua formação humana, reconhecendo-as como uma educação integral. Diferentemente das duas experiências analisadas por Coelho, Marques e Branco (2014), nas quais a escola é o locus central da aprendizagem, Coelho (2012) verifica que a concepção de Educação Integral observada em sua pesquisa, não tem a escola como centralidade nesse processo. A educação (em tempo) integral promove várias atividades com propósito mais assistencial do que educacional e essa visão de concepção integral vem sendo reforçada pela escola pública.

Em relação ao assistencialismo, Carvalho (2015) afirma que a educação integral tem um caráter de política social e ajuda a garantir alguns direitos das crianças. Além disso, a educação integral permite trazer à tona a vulnerabilidade a que muitas crianças estão expostas. $\mathrm{O}$ autor busca reafirmar a necessidade de a escola encarar os alunos como sujeitos de direito e evidencia que o papel assistencialista da escola integral nem sempre beneficia a todos os alunos que estão expostos a questões de vulnerabilidade. Porém, a educação (em tempo) integral pode representar uma transformação no papel da escola pública e acima disso contribuir para a garantia dos direitos e da cidadania das crianças.

Leite e Ramalho (2015) estudaram o PEI desenvolvido em Belo Horizonte (MG) e entrevistaram alunos que frequentaram o programa por pelo menos dois anos. De acordo com as autoras, as entrevistas apresentaram resultados positivos sobre o PEI. Alguns excertos dos ex-alunos mencionaram mudanças comportamentais, em relação a evitar confusões, ao respeito por regras e a ter disciplina. Além disso, apontam-se como essas mudanças de valores e atitudes influenciam positivamente nos seus meios de socialização e no mundo do trabalho; como a disciplina e o respeito são importantes para garantir um bom convívio social no ambiente de trabalho e fora dele. 
Ferreira e Rees (2015) estudam a Educação Integral e a Escola de Tempo Integral em Goiânia (GO), por meio de análise documental, observação participante e entrevistas com profissionais da escola. Observam que a escola de tempo integral no município não atende diretamente aos princípios da educação integral, pois as entrevistas realizadas com profissionais da escola evidenciam a falta de conhecimento em relação ao significado da educação integral. A coordenadora pedagógica em sua fala relata acreditar que a educação integral é trabalhada na escola, pelo fato dos alunos conseguirem uma boa nota no IDEB. Será que o bom resultado no IDEB comprova que a educação integral está sendo bem desenvolvida?

Por meio desse relato, pode-se notar que a concepção de educação integral não é clara para a coordenadora pedagógica e em outras entrevistas realizadas no artigo, as opiniões são bem divergentes dos princípios da educação integral. Alcançar um bom resultado no IDEB é algo importante para uma escola, mas isso não está diretamente associado à educação integral.

A educação integral ultrapassa o nível da instrução, procurando atingir o ser humano em todas as suas nuanças e potencialidades. Ademais, as avaliações nacionais procuram medir a qualidade do ensino-aprendizagem, mas não conseguem medir o nível de Educação que os educandos estão recebendo, para além da instrução (FERREIRA; REES, 2015, p. 242).

A educação integral tem uma função muito além de garantir melhorias na qualidade do ensino; está relacionada à formação completa e humana do sujeito. Para Ferreira e Rees (2015), a escola assume tantas funções que a aprendizagem fica em segundo ou até mesmo terceiro plano. Mais uma vez a visão assistencialista, na qual a escola retira os alunos da rua e oferece alimentação, higiene e saúde é presente no debate do artigo como uma concepção de educação integral.

Nesta experiência em Goiânia, Ferreira e Rees (2015) constatam que, na prática, a educação integral em tempo integral é realizada de forma diferente do que é previsto nos documentos oficiais do município. Os professores não possuem formação adequada para trabalhar com a educação integral, a escola não oferece estrutura condizente com as atividades prescritas e há muitas demandas, muitos alunos para poucos profissionais e os órgãos municipais não prestam a devida assistência.

Em comparação com o que foi mencionado pela coordenadora da experiência citada anteriormente (FERREIRA; REES, 2015), Soares (2014) analisa os resultados do projeto Escola de Tempo Integral na proficiência dos alunos do ensino fundamental das escolas públicas da rede estadual de Minas Gerais (MG). 
Por meio de análise e comparação dos resultados trazidos pelo PROEB (Programa de Avaliação da Educação Básica de Minas Gerais), Souza (2014) constata que há evidências que o Projeto Escola de Tempo Integral apresenta melhoria no desempenho escolar dos alunos, mas ainda resta dúvida quanto à magnitude desse efeito, pelas dificuldades encontradas em sua pesquisa. Portanto, a educação integral pode proporcionar melhorias no desenvolvimento escolar dos alunos e essa melhoria vem como um bônus de todas as atividades que estão previstas nos princípios da educação integral (SOUZA, 2014).

Branco (2012) em seu artigo "Desafios para a implantação da Educação Integral: análise das experiências desenvolvidas na região sul do Brasil", observa nas entrevistas realizadas com os pais dos alunos durante a sua pesquisa a mesma visão assistencialista sobre a função social da educação integral. A educação integral para muitos tem como função auxiliar as famílias que trabalham e não podem ficar com os filhos. Além disso, a autora aponta para a necessidade da formação continuada dos professores, que ainda é falha na região.

Em pesquisa realizada em algumas escolas da rede pública estadual de ensino fundamental do Estado de São Paulo, Castro e Lopes (2011) apontam para o mesmo fator social presente no projeto Escola de Tempo Integral. A intenção do governo teria sido resolver problemas sociais gerados pela ausência de políticas sociais. O projeto previa implementação, preferencialmente, em áreas com baixo Índice de Desenvolvimento Econômico, a fim de atender os menos favorecidos. A escola assumiu um papel de garantir refeições e segurança necessária para os alunos, assim, os pais podiam trabalhar tranquilamente.

Soares, Brandolin e Amaral (2017) estudam os desafios e dificuldades para a implementação do PME, sob a percepção dos atores a respeito das escolas, realizando entrevistas com diferentes profissionais da rede municipal de Petrópolis (RJ). Os entrevistados apontam, como maior dificuldade para a implementação do programa, a falta de infraestrutura na maioria das escolas. Novamente, a visão assistencialista se destaca como sendo a função primordial da educação integral.

Para Soares, Brandolin e Amaral (2017), o programa apresentou utilidade justamente por seu caráter assistencialista e não pela ampliação de oportunidades formativas para os alunos. Conclui-se nesse estudo que os profissionais possuem uma compreensão singular do programa, pois enxergam a ETI apenas como um programa assistencialista.

Diferente de todas as experiências relatadas nesta unidade, o artigo de Maciel, Jacomeli e Brasileiro (2017), "Fundamentos da Educação Integral Politécnica: da teoria à prática", 
apresenta um modelo de educação integral baseado nas concepções marxistas ${ }^{14}$. Essa proposta foi desenvolvida no município de Ariquemes em Rondônia, baseada no Projeto Burareiro de Educação Integral.

[...] a educação integral politécnica é uma alternativa às demais modalidades existentes. Diferencia-se dessas pela organicidade entre os princípios epistemológicos da pedagogia histórico-crítica e os processos educativos integrados, pelo alcance social e político, e, finalmente, por um tipo de gestão que pressupõe formação ampliada, embasada no conhecimento das demandas do desenvolvimento socioeconômico e nas urgências democráticas da sociedade (MACIEL; JACOMELI; BRASILEIRO, 2017, p. 484-485).

A educação integral politécnica busca possibilitar uma formação ampla para o mundo do trabalho, mas também uma visão histórico-crítica por parte dos alunos. Visa-se à emancipação das classes trabalhadoras e populares e a compreensão da natureza de classe da sociedade capitalista (MACIEL; JACOMELI; BRASILEIRO, 2017).

Os CIEPs serviram como inspiração para muitas experiências de educação integral aqui apresentadas. Cavaliere e Coelho (2003) analisam os Centros após 15 anos de sua implementação. O que mais chama a atenção é o fato de mencionarem, como ponto positivo, a perpetuação da ideia de educação integral, porém, as escolas parecem não realizar um trabalho que poderia ser qualificado como educação integral, ocorrendo apenas o prolongamento do tempo de permanência dos alunos nas escolas.

Apesar de esta unidade apresentar diferentes experiências de educação (em tempo) integral em diversas regiões do país, observa-se semelhanças entre os artigos. O fator mais presente é a concepção de assistencialismo social na ETI. Nesta concepção, a escola de tempo integral assume responsabilidades sociais a fim de ajudar as crianças e jovens menos favorecidos.

Outro fator muito discutido nos artigos é como a falta de infraestrutura e de recursos atrapalham a realização das atividades culturais, esportivas, profissionalizantes, entre outras, que são essenciais para a formação integral.

Foi possível observar também que os objetivos e princípios da educação (em tempo) integral não são bem trabalhados com os profissionais que atuam na ETI. Nota-se que alguns

\footnotetext{
${ }^{14}$ As concepções marxistas de educação são baseadas nos estudos da bibliografia de Karl Marx. "O conceito de politecnia decorre da concepção marxiana de educação. Essa concepção está expressa, em suas linhas gerais, nas "Instruções aos Delegados do Conselho Central Provisório, da Associação Internacional de Trabalhadores", publicadas em 1868 e que, em 1871, norteariam a política educacional da Comuna de Paris" (MACIEL; JACOMELI; BRASILEIRO, 2017, p. 474-475).
} 
acreditam que a ETI tem como função contribuir para o aumento dos índices educacionais e/ou atender as crianças e jovens menos favorecidos.

São destacados pontos positivos em várias experiências, o caráter transformador que a educação (em tempo) integral realiza na vida de muitas crianças e jovens. As atividades culturais, esportivas, entre outras, estimulam o desenvolvimento dos alunos, contribuindo para mudanças comportamentais e, acima disso, para uma formação integral do indivíduo, que leva em conta os seus gostos, os seus sentimentos, as questões físicas e biológicas do corpo humano e a sua personalidade.

\section{Organização dos conhecimentos e saberes na ETI}

A última unidade temática dedica-se à organização dos conhecimentos e saberes na educação (em tempo) integral e à importância da discussão acerca dos conhecimentos necessários para uma formação integral.

O artigo de Coelho e Maurício (2016) apresenta os conhecimentos - científicos, estéticos, éticos, corporais - trazidos para escola, refletindo "sobre a relação que esse espaço formal de ensino estabelece com os conhecimentos historicamente constituídos - universais ou locais, e sua apropriação pelas classes populares que nele se encontram" (COELHO; MAURÍCIO, 2016, p. 1096).

As autoras explicitam a questão da necessidade de os conhecimentos serem úteis à vida. É importante saber articular os conhecimentos para a vida com os conhecimentos de caráter científicos e estéticos. Consideram também a importância dos conhecimentos universais, historicamente constituídos pela escola, como necessários e imprescindíveis à emancipação das classes populares (COELHO; MAURÍCIO, 2016).

A tessitura de atividades diversificadas que a escola de tempo integral pode oferecer, reunindo os conhecimentos universais, historicamente constituídos, e aqueles da cultura local, vai revelar os conhecimentos praticados por ela, na busca da inclusão das crianças no contexto da sociedade em que vivem, possibilitando-lhes acessar e contribuir com toda a atividade humana que aquela cultura construiu (COELHO; MAURÍCIO, 2016, p. 1109).

No excerto acima, observa-se a quantidade de conhecimentos que pode ser agregado na ETI, os quais, em conjunto, contribuem para a ascensão das classes populares, ou seja, das minorias presentes na escola pública. As autoras apontam para o fato de que se a escola de tempo integral não se esforçar para que isso seja garantido e tiver como prioridade a proteção 
social, ao invés de incluir, ela levará à exclusão dessas crianças e jovens (COELHO; MAURÍCIO, 2016).

Fica clara a percepção de Coelho e Maurício (2016): a educação integral pode ter uma função de proteção social, mas a sua prioridade deve ser contribuir para a emancipação das classes populares, e isso só se dá por meio do conhecimento.

Souza e Charlot (2016) debatem sobre a relação que os alunos estabelecem com o saber na escola em tempo integral. Os autores realizaram a pesquisa no município de Governador Valadares localizado em Minas Gerais. Usaram como metodologia a adaptação do balanço de saber (CHARLOT, 2009) e entrevistas com os alunos. Nessas entrevistas muitos alunos afirmam aprender mais na ETI, mas alguns levam a ETI como um fardo.

O município analisado por Souza e Charlot (2016) aprovou a ETI levando em conta a necessidade de fortalecimento da identidade local, a compreensão da educação como um direito de todos, mas também, pela vulnerabilidade social de crianças e jovens. A proteção social entra como uma das questões primordiais para o desenvolvimento da ETI em Governador Valadares.

Souza e Charlot (2016) observam que a educação integral ainda permanece no "tempo do mesmo", pois são constantemente realizadas transcrições da lousa para o caderno dos alunos e do computador para o caderno, além de poucas atividades serem destinadas a cultura e esportes e o tempo das atividades permanecerem iguais, aula de 50 minutos, tempo pequeno para almoço e recreio. Eles afirmam que:

[...] há um esforço de rompimento com o tempo do mesmo, na organização do currículo por eixos temáticos e na construção de um projeto pedagógico em que todos os tempos da escola sejam educativos (tempo das aulas, das refeições, das oficinas) (SOUZA; CHARLOT, 2016, p. 1088).

Mesmo com esse esforço, há uma dificuldade em se estabelecer conhecimentos e atividades diferenciadas, ainda mais quando isso precisa estar alinhado com a organização do tempo. De acordo com os autores, os alunos desejam aprender arte, literatura, teatro, música, culinária, cultivo de hortas e plantas.

A escola em tempo integral só será um sucesso se ela conseguir ser um espaçotempo em que aprender tenha sentido, mobilize os alunos, traga para eles essa forma de prazer que se experimenta ao superar desafios. Com alguns alunos, que não gostam de aprender, o objetivo é construir o próprio sentido da escola. Com outros, que aliam boa vontade escolar e dificuldades para aprender, tratase de disponibilizar o tempo que permite aprender; não esqueçamos de que escola deriva de uma palavra grega que significa lazer; a escola é um lugar em que se deve ter tempo para aprender e não um lugar em que o professor corre, acompanhado por uns poucos alunos, enquanto os demais tentam aguentar. Com os alunos que gostam de aprender, a ETI pode ir mais longe, mas ela 
deve possibilitar que eles codefinam seus percursos de aprender. A todos os alunos, seja qual for a sua relação com a escola, a ETI pode oferecer oportunidades culturais novas (SOUZA; CHARLOT, 2016, p. 1089).

Souza (2016) realiza um estudo parecido com o citado acima, utilizando o mesmo aporte teórico e a mesma metodologia, o qual analisa a opinião de alunos que fazem parte das escolas em tempo integral localizadas no campo de Governador Valadares. Neste, os alunos, durante as entrevistas, revelam novamente o cansaço como um dos fatores que atrapalham a aprendizagem. Para alunos do campo, a jornada é ainda mais cansativa, pois precisam traçar um caminho a pé ou de ônibus até a escola. A autora considera que o tempo integral no campo não favorece o estabelecimento de relações mais estreitas entre os estudantes e a vida no campo, mesmo isso estando presente nas orientações curriculares do município.

Souza (2017) em seu artigo "Aprendizagens e tempo integral: entre a efetividade e o desejo", observa que mesmo com a ampliação do número de escolas, a quantidade de alunos reduziu, principalmente no $9^{\circ}$ ano do Ensino Fundamental, na rede de educação de Governador Valadares em Minas Gerais. A autora busca compreender os motivos de saída dos alunos, para isso realiza entrevistas e os balanços de saber (CHARLOT, 2009).

Analisando as respostas dos alunos, Souza (2017) atenta-se ao fato de os alunos se preocuparem mais com disciplinas como Português, Matemática, História, Ciências, obrigatórias no tempo parcial, pois as consideram mais importantes, tanto para passarem de ano como para ingressarem, futuramente, em uma universidade. Os alunos pensam na escola como algo válido para o futuro e não para o presente. Muitos associam a ETI como uma oportunidade de aprenderem mais, porque há mais tempo para dialogar com os professores e estudar. As aprendizagens intelectuais ficam em evidência.

Nesta unidade, Souza (2017) traz uma importante reflexão de que não basta ampliar o acesso à escola e à jornada escolar ampliada, sem se interrogar sobre o tipo de conhecimento veiculado na escola. É importante discutir acerca dos conhecimentos válidos a serem trabalhados na ETI. O currículo da ETI pode oferecer uma formação completa, abrangendo as disciplinas obrigatórias e as atividades que trabalham o corpo, a cultura e a interação social. Porém, desenvolver um currículo que vise à educação integral não é uma tarefa fácil, como observado em todos os textos apresentados nas unidades anteriores. 


\section{Considerações finais}

As unidades temáticas aqui exploradas trabalham dentro de diferentes campos envolvendo a educação (em tempo) integral. Os artigos discorrem acerca da necessidade de mudanças de caráter estrutural e pedagógico. Observamos, em sua maioria, apontamentos dos problemas enfrentados na implementação da ETI nas unidades escolares e sugestões de possíveis melhorias para se atingir, em sua totalidade, a educação (em tempo) integral.

A ampliação da jornada escolar, tão somente, não é suficiente para se garantir o que é previsto na legislação e na proposta de educação (em tempo) integral. O Brasil necessita de maiores investimentos, em capacitação para professores, aquisição de equipamentos e materiais, além da adequação da infraestrutura, ampliando e melhorando os prédios escolares.

O espaço, o tempo e os conhecimentos vinculados na ETI podem ser estruturalmente organizados de forma a atender a multidimensionalidade do sujeito. Torna-se necessário conectar o tempo com os conhecimentos e adaptá-los de forma que os alunos se sintam convidados a participar das atividades.

A gestão escolar pode estabelecer um fluxo de comunicação constante com a comunidade e com as famílias dos alunos, especialmente, para que assim a escola amplie seu alcance, abordando as relações existentes entre a comunidade e proporcionando um ensino democrático e comunitário.

A educação (em tempo) integral está relacionada com a ampliação dos territórios educativos, pois ampliar o espaço de aprendizagem e o convívio entre os alunos e a comunidade contribui para a formação integral do indivíduo, ajudando-o a usufruir dos espaços culturais e sociais que a região oferece e assim, desenvolvendo o sentimento de pertencimento ao local.

Apesar do diferente enfoque de cada um dos artigos, o princípio da educação (em tempo) integral permanece o mesmo, permeando todas as unidades. Este princípio é o de uma educação que compreende a multidimensionalidade do sujeito, visando à emancipação, à melhoria na qualidade do ensino e ao direito à educação.

Porém, a maioria das experiências relatadas nesses artigos não abordam este princípio de forma completa. A função social da educação (em tempo) integral parte de uma visão assistencialista. Atender os alunos que se encontram em vulnerabilidade social se torna o fator primordial para a implementação da educação (em tempo) integral, sendo este conceito perpetuado na maioria dos artigos.

A educação (em tempo) integral possibilita ao sujeito maiores oportunidades, tanto no âmbito educacional como no profissional, mas sua função principal é formá-lo de forma que 
compreenda os seus direitos, os seus sentimentos, a sociedade que está inserido e se faça presente nela.

A formação integral ultrapassa as questões sociais e econômicas, sendo estendida a uma formação pessoal, íntima. A visão multidimensional do sujeito precisa ser o ponto de partida para que a educação (em tempo) integral não perca a sua identidade.

\section{REFERÊNCIAS}

AZEVEDO, N. C. S.; BETTI, M. Escola de tempo integral e ludicidade: os pontos de vista de alunos do $1^{\circ}$ ano do ensino fundamental. Rev. bras. Estud. Pedagog., Brasília, v. 95, n. 240, p. 255-275, maio/ago. 2014. Disponível em: http://www.scielo.br/pdf/rbeped/v95n240/02.pdf. Acesso em: 23 nov. 2019.

BERNADO, E. S.; CHRISTOVÃO, A. C. Tempo de Escola e Gestão Democrática: o Programa Mais Educação e o IDEB em busca da qualidade da educação. Educação \& Realidade, Porto Alegre, v. 41, n. 4, p. 1113-1140, out./dez. 2016. Disponível em: http://www.scielo.br/pdf/edreal/v41n4/2175-6236-edreal-41-04-01113.pdf. Acesso em: 23 nov. 2019.

BRANCO, V. Desafios para a implantação da Educação Integral: análise das experiências desenvolvidas na região sul do Brasil. Educar em Revista, Curitiba, n. 45, p. 111-123, jul./set. 2012. Disponível em: http://www.scielo.br/pdf/er/n45/08.pdf. Acesso em: 7 nov. 2019.

BRASIL. Decreto n. 7.083, de 27 de janeiro de 2010. Dispõe o Programa Mais Educação. Brasília, DF: MEC, 2010. Disponível em: http://www.planalto.gov.br/ccivil_03/_Ato20072010/2010/Decreto/D7083.htm. Acesso em: 7 nov. 2019.

BRASIL. Lei n. 12.796, de 4 de abril de 2013. Altera a Lei no. 9.394, de 20 de dezembro de 1996, que estabelece as diretrizes e bases da educação nacional, para dispor sobre a formação dos profissionais da educação e dar outras providências. Brasília, DF: MEC, 2013. Disponível em: http://www.planalto.gov.br/ccivil_03/_Ato2011-2014/2013/Lei/L12796.htm\#art1. Acesso em: 03 abr. 2020.

BRASIL. Lei n. 13.005, de 25 de junho de 2014. Aprova o Plano Nacional de Educação PNE e dá outras providências. Brasília, DF: MF/MP/MEC, 2014. Disponível em: http://www.planalto.gov.br/ccivil_03/_ato2011-2014/2014/lei/113005.htm. Acesso em: 6 nov. 2019.

BRASIL. Lei n. 9.394, de 20 de dezembro de 1996. Estabelece as diretrizes e bases da educação nacional. Brasília, DF: MEC, 1996. Disponível em: http://www.planalto.gov.br/ccivil_03/leis/L9394.htm. Acesso em: 6 nov. 2019.

BRASIL. Ministério da Educação - MEC. Saiba Mais - Programa Mais Educação.

Disponível em: http://portal.mec.gov.br/programa-mais-educacao/apresentacao?id=16689. Acesso em: 09 jan. 2020. 
BRASIL. Portaria normativa interministerial n. 17, de 24 de abril de 2007. Institui o Programa Mais Educação. Brasília, DF: MEC, 2007. Disponível em:

http://portal.mec.gov.br/arquivos/pdf/mais_educacao.pdf. Acesso em: 6 nov. 2019.

BRASIL. Portaria normativa interministerial n. 17, de 24 de abril de 2007. Institui o Programa Mais Educação. Brasília, DF: MEC. Disponível em:

http://portal.mec.gov.br/arquivos/pdf/mais_educacao.pdf. Acesso em: 6 nov. 2019.

BRASIL.IDEB. Instituto Nacional de Estudos e Pesquisas (INEP). Brasília, DF: MEC. Disponível em: http://portal.inep.gov.br/ideb. Acesso em: 21 nov. 2019.

CARVALHO, L. D. Crianças e infâncias na educação (em tempo) integral. Educação em Revista, Belo Horizonte, v. 31, n. 4, p. 23-43, out./dez. 2015. Disponível em:

http://www.scielo.br/pdf/edur/2015nahead/0102-4698-edur-136686.pdf. Acesso em: 20 nov. 2019.

CASTRO, A.; LOPES, R. E. A escola de tempo integral: desafios e possibilidades. Ensaio: aval. pol. públ. Educ., Rio de Janeiro, v. 19, n. 71, p. 259-282, abr./jun. 2011. Disponível em: http: http://www.scielo.br/pdf/ensaio/v19n71/a03v19n71.pdf. Acesso em: 23 nov. 2019.

CAVALIERE, A. M. Escola pública de tempo integral no brasil: filantropia ou política de estado? Educ. Soc., Campinas, v. 35, n. 129, p. 1205-1222, out./dez. 2014. Disponível em: http://www.scielo.br/pdf/es/v35n129/0101-7330-es-35-129-01205.pdf. Acesso em: 30 out. 2019.

CAVALIERE, A. M.; COELHO, L. M. Para onde caminham os Cieps? Uma análise após 15 anos. Cadernos de Pesquisa, São Paulo, n. 119, p. 147-174, jul. 2003. Disponível em: http://www.scielo.br/pdf/cp/n119/n119a08.pdf. Acesso em: 6 nov. 2019.

CHARLOT, B. A relação com o saber nos meios populares: uma investigação nos liceus profissionais de subúrbio. Porto: Livpsic, 2009.

COELHO, L. M. C. C. Alunos no ensino fundamental, ampliação da jornada escolar e educação integral. Educar em Revista, Curitiba, Brasil, n. 45, p. 73-89, jul./set. 2012. Disponível em: http://www.scielo.br/pdf/er/n45/06.pdf. Acesso em: 19 nov. 2019.

COELHO, L. M. C. C.; MARQUES, L. P.; BRANCO, V. Políticas públicas municipais de educação integral e(m) tempo ampliado: quando a escola faz a diferença. Ensaio: aval. pol. públ. Educ., Rio de Janeiro, v. 22, n. 83, p. 355-378, abr./jun. 2014. Disponível em: http://www.scielo.br/pdf/ensaio/v22n83/a05v22n83.pdf. Acesso em: 19 nov. 2019.

COELHO, L. M. C. C.; MAURÍCIO, L. V. Sobre tempo e conhecimentos praticados na escola de tempo integral. Educação \& Realidade, Porto Alegre, v. 41, n. 4, p. 1095-1112, out./dez. 2016. Disponível em: http://www.scielo.br/scielo.php?pid=S217562362016005005102\&script=sci_abstract\&tlng=pt. Acesso em: 19 nov. 2019.

CURY, C. R. J.; CUNHA, C. da (Org.). O Manifesto educador: os pioneiros 80 anos depois. Rev. bras. Estud. pedagog., Brasília, v. 96, n. esp., 2015. Disponível em: http://portal.inep.gov.br/documents/186968/489316/O+Manifesto+Educador+Os+Pioneiros+8 
0+Anos+Depois/588cfd88-e167-4d02-b810-cbafa1dce05d?version=1.2. Acesso em: 2 fev. 2020.

FERREIRA, H. B.; REES, D. K. Educação integral e escola de tempo integral em Goiânia. Educação \& Realidade, Porto Alegre, v. 40, n. 1, p. 229-251, jan./mar. 2015. Acesso em: http://www.scielo.br/pdf/edreal/v40n1/2175-6236-edreal-40-01-00229.pdf. Acesso em: 19 nov. 2019.

GONÇALVES, A. S. Reflexões sobre educação integral e escola de tempo integral.

Cadernos Cenpec, São Paulo, v. 1, n. 6, p. 129-135, 2006. Disponível em:

http://cadernos.cenpec.org.br/cadernos/index.php/cadernos/article/view/136. Acesso em: 12 nov. 2019.

GOOGLE. Como funciona a Pesquisa Google. Disponível em:

https://www.google.com/search/howsearchworks. Acesso em: 13 nov. 2019.

LEITE, L. H. A. Educação integral, territórios educativos e cidadania: aprendendo com as experiências de ampliação da jornada escolar em Belo Horizonte e Santarém. Educar em Revista, Curitiba, n. 45, p. 57-72, jul./set. 2012. Disponível em: http://www.scielo.br/pdf/er/n45/05.pdf. Acesso em: 16 nov. 2019.

LEITE, L. H. A.; CARVALHO, P. F. L. de. Educação (de tempo) integral e a constituição de territórios educativos. Educação \& Realidade, Porto Alegre, v. 41, n. 4, p. 1205-1226, out./dez. 2016. Disponível em: http://www.scielo.br/pdf/edreal/v41n4/2175-6236-edreal-4104-01205.pdf. Acesso em: 16 nov. 2019.

LEITE, L. H. A.; RAMAHO, B. Jovens-adolescentes egressos de uma educação integral: a construção de atitudes e valores. Educação em Revista, Belo Horizonte, v. 31, n. 4, p. 63-80, out./dez. 2015. Disponível em: http://www.scielo.br/pdf/edur/v31n4/1982-6621-edur-31-0400063.pdf. Acesso em: 16 nov. 2019.

MACIEL, A. C.; JACOMELI, M. R. M.; BRASILEIRO, T. S. A. Fundamentos da educação integral politécnica: da teoria à prática. Educ. Soc., Campinas, v. 38, n. 139, p. 473-488, abr./jun. 2017. Disponível em: http://www.scielo.br/pdf/es/v38n139/1678-4626-es-38-13900473.pdf. Acesso em: 16 nov. 2019.

MARCONI, M. A.; LAKATOS, E. M. Fundamentos de metodologia científica. 7. ed. São Paulo: Atlas, 2010.

MEDEIROS, J. B. Redação científica: a prática de fichamentos, resumos, resenhas. 8. ed. São Paulo: Atlas, 2006.

PARO, V. H. Gestão escolar, democracia e qualidade do ensino. 1. ed. São Paulo: Ática, 2009.

SANTOS, S. V. A ampliação do tempo escolar em propostas de educação pública integral. Orientadora: Marília Gouvea de Miranda. 2009. 138 f. Dissertação (Mestrado em Educação) - Universidade Federal de Goiás, Goiânia, 2009. Disponível em: http://ppge.fe.ufg.br/up/6/o/Dissert-\%20Soraya.pdf. Acesso em: 08 jan. 2020. 
SOARES, A. J. G.; BRANDOLIN, F.; AMARAL, D. P. do. Desafios e dificuldades na implementação do Programa Mais Educação: percepção dos atores das escolas. Educação \& Realidade, Porto Alegre, v. 42, n. 3, p. 1059-1079, jul./set. 2017. Disponível em: http://www.scielo.br/pdf/edreal/v42n3/2175-6236-edreal-60490.pdf. Acesso em: 16 nov. 2019.

SOARES, T. M. et al. Escola de tempo integral: resultados do projeto na proficiência dos alunos do ensino fundamental das escolas públicas da rede estadual de Minas Gerais. Ensaio: aval. pol. públ. Educ., Rio de Janeiro, v. 22, n. 82, p. 111-130, jan./mar. 2014. Disponível em: http://www.scielo.br/pdf/ensaio/v22n82/a06v22n82.pdf. Acesso em: 16 nov. 2019.

SOUSA, I. F.; GUIMARÃES-IOSIF, R.; ZARDO, S. P. As redes da educação integral no Distrito Federal sob o prisma da gestão escolar. Ensaio: aval. pol. públ. Educ., Rio de Janeiro, v. 26, n. 99, p. 397-417, abr./jun. 2018. Disponível em: http://www.scielo.br/pdf/ensaio/v26n99/1809-4465-ensaio-S0104-40362018002601432.pdf. Acesso em: 13 nov. 2019.

SOUZA, M. C. R. F. Aprendizagens e tempo integral: entre a efetividade e o desejo. Ensaio: aval. pol. públ. Educ., Rio de Janeiro, v. 25, n. 95, p. 414-439, abr./jun. 2017. Disponível em: http://www.scielo.br/pdf/ensaio/v25n95/1809-4465-ensaio-S010440362017002500483 .pdf. Acesso em: 16 nov. 2019.

SOUZA, M. C. R. F. Estudantes em tempo integral no campo: aprendizagens, processos e sentidos. Cadernos de Pesquisa, São Paulo, v. 46, n. 161, p. 756-782, jul./set. 2016. Disponível em: http://www.scielo.br/pdf/cp/v46n161/1980-5314-cp-46-161-00756.pdf. Acesso em: 13 nov. 2019.

SOUZA, M. C. R. F. Tempo integral: tensões entre os tempos da escola e os tempos do corpo. Educar em Revista, Curitiba, v. 34, n. 67, p. 159-175, jan./fev. 2018. Disponível em: http://www.scielo.br/pdf/er/v34n67/0104-4060-er-34-67-159.pdf. Acesso em: 13 nov. 2019.

SOUZA, M. C. R. F.; CHARLOT, B. Relação com o saber na escola em tempo integral. Educação \& Realidade, Porto Alegre, v. 41, n. 4, p. 1071-1093, out./dez. 2016. Disponível em: http://www.scielo.br/pdf/edreal/v41n4/2175-6236-edreal-59843.pdf. Acesso em: 16 nov. 2019.

TEIXEIRA, A. S. Educação não é privilégio. 5. ed. Rio de Janeiro: Editora UFRJ, 1994.

TORALES, M. A. Entre kronos e kairós: o sentido e as implicações da ampliação do tempo de permanência dos estudantes na escola. Educar em Revista, Curitiba, n. 45, p. 125-135, jul./set. 2012. Disponível em: http://www.scielo.br/pdf/er/n45/09.pdf. Acesso em: 13 nov. 2019. 


\section{Como referenciar este artigo}

VILAS BOAS, M. L.; ABBIATI, A. S. A educação (em tempo) integral no brasil: um olhar sobre diferentes experiências. Revista on line de Política e Gestão Educacional, Araraquara, v. $24, \quad$ n. 3 , p. 1573-1597, set./dez. 2020. e-ISSN:1519-9029. DOI: https://doi.org/10.22633/rpge.v24i3.13545

Submetido em: 06/04/2020

Revisões requeridas: $20 / 07 / 2020$

Aprovado em: 10/10/2020

Publicado em: 01/09/2020 